\title{
Antimelanogenic and antioxidant activities of Bifidobacterium infantis
}

\author{
Huey-Chun Huang', Shao-Hua Chiu' ${ }^{2}$, Hui-Ju Ke ${ }^{2}$, Shu-wen $\mathrm{Chiu}^{2}$, Sze-Yun Wu${ }^{2}$ and \\ Tsong-Min Chang ${ }^{2 *}$
}

\author{
${ }^{1}$ Department of Medical Laboratory Science and Biotechnology, China Medical University, Taichung, Taiwan, \\ Republic of China. \\ ${ }^{2}$ Department of Applied Cosmetology and Graduate Institute of Cosmetic Science, Hung Kuang University, Taichung, \\ Taiwan, Republic of China.
}

Accepted 15 June, 2011

\begin{abstract}
The study was aimed at investigating the antimelanogenic and antioxidative effects of Bifidobacterium infantis culture filtrate. The efficacy of the bacterial culture filtrate was evaluated spectrophotometrically. The results revealed that $B$. infantis culture filtrate effectively scavenge 2,2diphenyl-1-picryl-hydrazyl (DPPH) and 2,2'-azino-bis(3-ethylbenzthiazoline-6-sulphonic acid) ABTS radicals, and show potent reducing power in a dose-dependent pattern. Additionally, the bacterial culture filtrate suppresses murine B16F10 tyrosinase activity and the amount of melanin in a dosedependent manner. We conclude that the $B$. infantis culture filtrate may be applied in the formulations of skin care cosmetics.
\end{abstract}

Key words: Bifidobacterium infantis, tyrosinase, melanin, antioxidant.

\section{INTRODUCTION}

Melanin plays an important role in protection the skin against ultraviolet light (UV) light injury and is responsible for skin color. It is reported that overproduction and accumulation of melanin result in several skin disorders such as melasma, age spots, other hyperpigmentation syndrome and freckles (Briganti et al., 2003). Tyrosinase is the rate-limiting enzyme in melanin biosynthesis pathway (Seo et al., 2003). It has been evidenced that other enzymes such as tyrosinase-related protein-1

${ }^{\star}$ Corresponding author. E-mail: ctm@sunrise.hk.edu.tw. Tel: 886-4-26318652. Ext. 5300. Fax: 886-4-26321046.

Abbreviations: DPPH, 2,2-Diphenyl-1-picryl-hydrazyl; ABTS, 2, 2'-azino-bis (3-ethylbenzthiazoline-6-sulphonic acid; TRP-1, tyrosinase-related protein-1; TRP-2, tyrosinase-related protein2; UV, ultraviolet; ROS, reactive oxygen species; GSH, glutathione; BCRC, bioresource collection and research center; MRS, man rogosa sharp; MC1R, melanocortin 1 receptor; BHA, butylated hydroxyanisole
(TRP-1) and tyrosinase-related protein-2 (TRP-2) also contribute to the production of melanin (Hearing and Jimenez, 1987; Tsukamoto et al., 1992; JimenezCervantes et al., 1994). Recently, various inhibitors of melanogenesis have been applied in skin care products for the prevention of hyperpigmentation (Funasaka et al., 2000). Active oxygen species and free radicals have been recognized as important factors in the pathogenesis of human diseases such as atherosclerosis, aging and cancer (Halliwell et al., 1992). It is reported that UV exposure generates reactive oxygen species (ROS) and excessive ROS are associated with several skin disorders (Yasui and Sakurai, 2003). Additionally, it is reported that melanogenesis produce hydrogen peroxide $\left(\mathrm{H}_{2} \mathrm{O}_{2}\right)$ and other ROS which makes the melanocytes under low-grade oxidative stress. It is evidenced that ROS scavengers and inhibitors of ROS generation may down-regulate melanogenesis-induced by UV exposure (Yamakoshi et al., 2003).

Therefore, antioxidants such as ascorbic derivatives and reduced glutathione (GSH) have been applied as 
inhibitory agents of melanogenesis (Imokawa, 1989; Kumano et al., 1998). Bifidobacteria are gram-positive obligate anaerobes and considered to promote the health of host intestinal tract because of their beneficial effects including reduction of harmful bacteria and toxic compounds, regulation of the state of the intestine, modulation of immune response and anticancer activity (Gibson and Wang, 1994; Hooper and Gordon, 2001; Femia et al., 2002; Ouwehand et al., 2002). Besides, it is reported that orally administered Bifidobacteria species can improve nutritional value of food and control intestinal infections (Gilliland, 1990). Recently, numerous human clinical trials suggested that probiotic supplementation might be useful in the treatment of atopic dermatitis (Kalliomaki et al., 2001; Rautava and Isolauri, 2002; Kalliomaki et al., 2003; Kalliomaki et al., 2007; Puch et al., 2008). Moreover, some reports have demonstrated that certain bacterial extracts including Lactobacillus johnsonii, Lactobacillus casei, Lactobacillus plantarum and Lactobacillus acidophilus, have anti-microbial and anti-adhesion properties when applied to cutaneous and mucous surfaces (Ouwehand et al., 2003; Rodriguez et al., 2005). Furthermore, B. infantis has been reported to show several therapeutic effects such as prevention of interferon-gamma-induced keratinocyte apoptosis, antiinflammation activity and protective effects for colitis (Cinque et al., 2006; Tanabe et al., 2008; Van der Kleij et al., 2008). However, there is no report about application of $B$. infantis culture filtrate in cosmetics for potential skin care use. In the present study, we attempted to investigate the effects of $B$. infantis culture filtrate on the mushroom tyrosinase activity, intracellular tyrosinase activity and melanin content in B16F10 murine melanoma cells. Moreover, we looked into the inhibitory effect of $B$. infantis culture filtrate on melanogenesis associated with its antioxidant properties by assessing its antioxidant and free radical scavenging activities.

\section{MATERIALS AND METHODS}

\section{Bacterial culture}

The $B$. infantis strain (BCRC 14602) was obtained from the Bioresource Collection and Research Center (BCRC), Food Industry Research and Development Institute, Hsinchu, Taiwan. The bacterial strain was cultivated in Man Rogosa Sharp (MRS) broth (Difco, Detroit, MI and USA) supplemented with $0.4 \mathrm{~g} / \mathrm{I}$ cysteine-HCl (Sigma Chemical Co. St. Louis, USA) anaerobically overnight at $37^{\circ} \mathrm{C}$. Before experimental use, bacterial strain was subcultured twice in cysteine-containing MRS broth. After that, $1 \%$ $(\mathrm{v} / \mathrm{v})$ of each culture was transferred to a $50 \mathrm{ml}$ cysteine- containing MRS broth and incubated anaerobically at $37^{\circ} \mathrm{C}$ for $48 \mathrm{~h}$ in an anaerobic incubation system (ThermoForma, Model 1025, Marietta, USA) that was continuously sparged with a mixture of $10 \%$ carbon dioxide, $10 \%$ hydrogen and $80 \%$ nitrogen (Toyogas, Taichung and Taiwan). After incubation, bacterial cells were removed by centrifugation $\left(10,000 \mathrm{~g} / 10 \mathrm{~min} / 4^{\circ} \mathrm{C}\right)$ and supernatant was passed through a cellulose acetate filter $(0.45 \mu \mathrm{m})$ to get bacterial culture filtrate.

\section{Determination of antimelanogenic activity}

\section{Anti-mushroom tyrosinase assay}

In order to assay the potential inhibitory effects of $B$. infantis culture filtrate on mushroom tyrosinase, dose-dependent inhibition experiments were carried out in triplicate as described previously with a minor modification (Bilodeau et al., 2001). Briefly, $10 \mu \mathrm{l}$ of aqueous solution of mushroom tyrosinase (1000 units) was added to a 96 well microplate, in a total volume of $200 \mu \mathrm{l}$ mixture containing $5 \mathrm{mM}$ $\mathrm{L}$-dopa dissolved in $50 \mathrm{mM}$ phosphate buffer ( $\mathrm{pH} \mathrm{6.8).} \mathrm{The} \mathrm{assay}$ mixture was incubated at $37^{\circ} \mathrm{C}$ for $30 \mathrm{~min}$. Following incubation, the amount of dopachrome produced in the reaction mixture was determined by spectrophotometric analysis at $490 \mathrm{~nm}$ absorbance.

\section{Intracellular melanin content measurement}

B16F10 melanoma cells (ATCC CRL-6475; BCRC60031) were cultured in DMEM with $10 \%$ fetal bovine serum (FBS; Gibco, NY and USA) and penicillin/ streptomycin (100 IU/50 $\mu \mathrm{g} / \mathrm{ml})$ in a humidified atmosphere containing $5 \% \quad \mathrm{CO}_{2}$ in air at $37^{\circ} \mathrm{C}$. Intracellular melanin content was measured as described by Tsuboi et al. (1998) with some modifications (Tsuboi et al., 1998). The cells were treated with $\alpha-\mathrm{MSH}(100 \mathrm{nM})$ for $24 \mathrm{~h}$ and further treated with either $B$. infantis culture filtrate (final concentration 1.0, 2.5, 5.0, 7.5 $\% \mathrm{v} / \mathrm{v})$ or kojic acid $(200 \mu \mathrm{M})$ or arbutin $(1 \mathrm{mM})$ for another $24 \mathrm{~h}$. After treatments, the cells were detached by incubation in trypsin/EDTA and subsequently centrifuged at $5,000 \mathrm{~g}$ for $5 \mathrm{~min}$, and then the cell pellets were solubilized in $1 \mathrm{~N} \mathrm{NaOH}$ at $60^{\circ} \mathrm{C}$ for $60 \mathrm{~min}$. The melanin content was assayed by spectrophotometric analysis at $405 \mathrm{~nm}$ absorbance.

\section{Intracellular tyrosinase activity assay}

B16F10 intrcellular tyrosinase activity was determined as described previously with slight modifications (Yeh Yang et al., 2006). Briefly, the cells were treated with $\alpha-\mathrm{MSH}(100 \mathrm{nM})$ for $24 \mathrm{~h}$ and then further treated with various concentrations of $B$. infantis culture filtrate (final concentration $1.0,2.5,5.0,7.5 \% \mathrm{v} / \mathrm{v}$ ) or kojic acid (200 $\mu \mathrm{M})$ or arbutin $(1 \mathrm{mM})$ for another $24 \mathrm{~h}$. After treatments, the cells were washed twice with phosphate-buffered saline and homogenized with $50 \mathrm{mM}$ PBS $(\mathrm{pH} 7.5)$ buffer containing $1.0 \%$ Triton X-100 and $0.1 \mathrm{mM}$ PMSF. Cellular extracts $(100 \mu \mathrm{l})$ were mixed with freshly prepared L-Dopa solution $(0.1 \%$ in phosphatebuffered saline) and incubated at $37^{\circ} \mathrm{C}$ for $30 \mathrm{~min}$. The absorbance at $490 \mathrm{~nm}$ was measured with a microplate reader Gen $5^{\mathrm{TM}}$ (BIOTEK Instrument, USA) to monitor the production of dopachrome.

\section{Determination of antioxidant activity}

\section{DPPH scavenging activity assay}

The antioxidant activity of $B$. infantis culture filtrate was first determined by measuring the DPPH scavenging ability (BrandWilliams et al., 1995) as modified by Sanchez-Moreno et al. (1998). Bacterial culture filtrates at various concentrations (final concentration $2.5,5.0,7.5 \% \mathrm{v} / \mathrm{v})$ were added to $2.9 \mathrm{ml}$ of DPPH (60 $\mu \mathrm{M})$ solution. When DPPH reacts with an antioxidant that can donate hydrogen, it gets reduced form and the resulting decrease in absorbance at $517 \mathrm{~nm}$ was recorded using a UV-Vis spectrophotometer (Jasco, V-630, UV-Vis spectrophotometer). In this study, vitamin $\mathrm{C}(50 \mu \mathrm{M})$ and vitamin $\mathrm{E}(50 \mu \mathrm{M})$ were used as antioxidant standards. 


\section{ABTS $^{+}$scavenging capacity assay}

The ABTS decolorisation assays were carried out as previously described (Re et al. 1999) and it involves the generation of $\mathrm{ABTS}^{+}$ chromophore by oxidation of ABTS with potassium persulfate. The ABTS radical cation $\left(\mathrm{ABTS}^{+}\right)$was produced by reacting $7 \mathrm{mM}$ stock solution of ABTS with $2.45 \mathrm{mM}$ potassium persulfate and allowing the mixture to stand in the dark for at least $6 \mathrm{~h}$ before use. Absorbance at $734 \mathrm{~nm}$ was measured $10 \mathrm{~min}$ after mixing of different concentrations of the $B$. infantis culture filtrate (final concentration $2.5,5.0,7.5 \% \mathrm{v} / \mathrm{v}$ ) with $1 \mathrm{ml}$ of $\mathrm{ABTS}^{+}$solution. The $\mathrm{ABTS}^{+}$scavenging capacity of the filtrate was compared with that of vitamin $\mathrm{C}(60 \mu \mathrm{M})$ and vitamin $\mathrm{E}(60 \mu \mathrm{M})$.

\section{Determination of reducing power}

The reducing power of the extract was determined according to the method of Oyaizu (1986). Different concentrations of the bacterial filtrate or vitamin $\mathrm{C}(44 \mu \mathrm{M})$ or vitamin $\mathrm{E}(44 \mu \mathrm{M})$ was mixed with phosphate buffer $(2.5 \mathrm{ml}, 0.2 \mathrm{M}$ and $\mathrm{pH} 6.6)$ and potassium ferricyanide $\left[\mathrm{K}_{3} \mathrm{Fe}(\mathrm{CN})_{6}\right](2.5 \mathrm{ml}, 1 \% \mathrm{w} / \mathrm{v})$. The mixture was incubated at $50^{\circ} \mathrm{C}$ for $20 \mathrm{~min}$. A portion $(2.5 \mathrm{ml})$ of trichloroacetic acid $(10 \% \mathrm{w} / \mathrm{v})$ was added to the mixture, which was then centrifuged at $1000 \mathrm{~g}$ for $10 \mathrm{~min}$. The upper layer of solution $(2.5$ $\mathrm{ml})$ was mixed with distilled water $(2.5 \mathrm{ml})$ and $\mathrm{FeCl}_{3}(0.5 \mathrm{ml}, 0.1 \%$ $\mathrm{w} / \mathrm{v}$ ) and the absorbance was measured at $700 \mathrm{~nm}$ in a UV-Vis spectrophotometer. Higher absorbance of the reaction mixture indicated greater reducing power.

\section{Statistical analysis}

Statistical analysis of the experimental data points was performed by the ANOVA test, which was used for comparison of measured data using SPSS 12.0 statistical software (SPSS INC. Chicago, USA). Differences were considered as statistically significant at $p<$ 0.05 .

\section{RESULTS AND DISCUSSION}

To determine the potential whitening activity of $B$. infantis culture filtrate, the potential inhibitory effects of the bacterial culture filtrate on mushroom tyrosinase and B16F10 intracellular tyrosinase activities were assayed. Furthermore, the melanin content in B16F10 cells was also measured after treatment with the culture filtrate or positive standards. Figure $1 \mathrm{~A}$ indicated that the mushroom tyrosinase activity was inhibited by different concentrations of $B$. infantis culture filtrate in a dosedependent manner. The remaining tyrosinase activity was $65.2 \pm 4.8,12.7 \pm 2.9$ and $1.2 \pm 0.25 \%$ for $7.5,15$ and $20 \%$ of bacterial culture filtrate, respectively (Figure $1 \mathrm{~A}$ ). Meanwhile, the remaining tyrosinase activity was $45.2 \pm$ $5.5 \%$ for kojic acid. However, lower concentrations of the bacterial filtrate $(1.0,2.5,5.0 \% \mathrm{v} / \mathrm{v})$ did not show apparent tyrosinase inhibitory activity (data not shown). To determine the effect of $B$. infantis culture filtrate on melanogenesis, B16F10 melanoma cells were stimulated with $100 \mathrm{nM} \mu-\mathrm{MSH}$ for $24 \mathrm{~h}$ and cultured in the presence of $B$. infantis culture filtrate $(1.0,2.5,5.0$ and $7.5 \% \mathrm{v} / \mathrm{v})$, kojic acid $(200 \mu \mathrm{M})$ or arbutin $(2 \mathrm{mM})$ for another $24 \mathrm{~h}$.
After treatment, the melanin content was $77.1 \pm 1.5,73.5$ $\pm 2.6,64.3 \pm 2.1,51.5 \pm 2.3 \%$ for $1.0,2.5,5.0$ and $7.5 \%$ of bacterial culture filtrate, respectively (Figure 1B).

Meanwhile, the melanin content was $86.4 \% \pm 1.8 \%$ for kojic acid and $70.6 \pm 2.3 \%$ for arbutin. Furthermore, $B$. infantis culture filtrate significantly inhibited $\mu-\mathrm{MSH}$ induced tyrosinase activity in a dose-dependent pattern (Figure 1C). After those treatments, the remained B16F10 intracellular tyrosinase activity was $94.5 \pm 4.4,81.04 \pm$ $3.5,51.1 \pm 3.8,21.8 \pm 2.9 \%$ for $1.0,2.5,5.0$ and $7.5 \%$ of bacterial culture filtrate, respectively. Meanwhile, the intracellular tyrosinase activity $93.7 \pm 1.3 \%$ for kojic acid and $89.4 \pm 4.6 \%$ for arbutin. Chronic exposure to solar UV radiation plays a key role in the initiation of several skin disorders, including scaling, wrinkling, dryness and mottled pigment abnormalities such as hypopigmentation and hyperpigmentation (Ichihashi et al., 2003; Mukhtar and Elmets, 1996). Therefore, there is an increasing need for new and effective agents which perform photo protection and skin whitening activities to prevent the above skin disorders. So far, there is no report about the effect of probiotic bacterial culture filtrate on melanin production. The results shown in Figure $1 \mathrm{C}$ were in accordance with the results indicated in Figure $1 \mathrm{~B}$, which means $B$. infantis culture filtrate inhibit intracellular tyrosinase activity and then decrease the melanin content in a dose-dependent manner in B16F10 melanoma cells.

In the experiments, $\mu$-MSH was used as a cAMP inducer to stimulate melanin synthesis. It is evidenced that $\alpha$ MSH can bind melanocortin 1 receptor (MC1R) and activate adenylate cyclase, which in turn catalyzes ATP to cAMP and increases intracellular cAMP level (Ballotti, 2000). In this report, the results show that $B$. infantis culture filtrate inhibited melanogenesis induced by $\mu-\mathrm{MSH}$ mediated intracellular cAMP up-regulation. The skin is exposed to UV and environmental oxidizing pollutants and is a preferred target of oxidative stress. It is reported that UV irradiations induce the formation of ROS in cutaneous tissue provoking toxic changes such as lipid peroxidation and enzyme inactivation (Emerit, 1992). To counteract the oxidative damage, skin is equipped with a network of enzymatic and non-enzymatic antioxidant systems. To elucidate the antioxidant activity of $B$. infantis culture filtrate, $\mathrm{DPPH}, \mathrm{ABTS}^{+}$radical scavenging activity and reducing power of the bacterial culture filtrate was determined as described previously. Figure $2 \mathrm{~A}$ shows the DPPH radical scavenging activity of $B$. infantis culture filtrate is increased in a dose-dependent manner and the radical scavenging activity was $56.76 \pm 1.1,60.5 \pm 5.5$, $91.7 \pm 3.0 \%$ for $2.5,5.0$ and $7.5 \%$ of bacterial culture filtrate, respectively. The DPPH radical scavenging activity of vitamin $C$ was $43.5 \pm 1.13 \%$ and that of vitamin E was $35.9 \pm 1.74 \%$. Figure $2 \mathrm{~B}$ depicts the $\mathrm{ABTS}^{+}$radical cation absorption capacity of various concentrations of $B$. infantis culture filtrate.

The radical scavenging activity for $2.5,5.0$ and $7.5 \%$ of bacterial culture filtrate was $51.4 \pm 1.3,59.9 \pm 1.5,84.4 \pm$ 

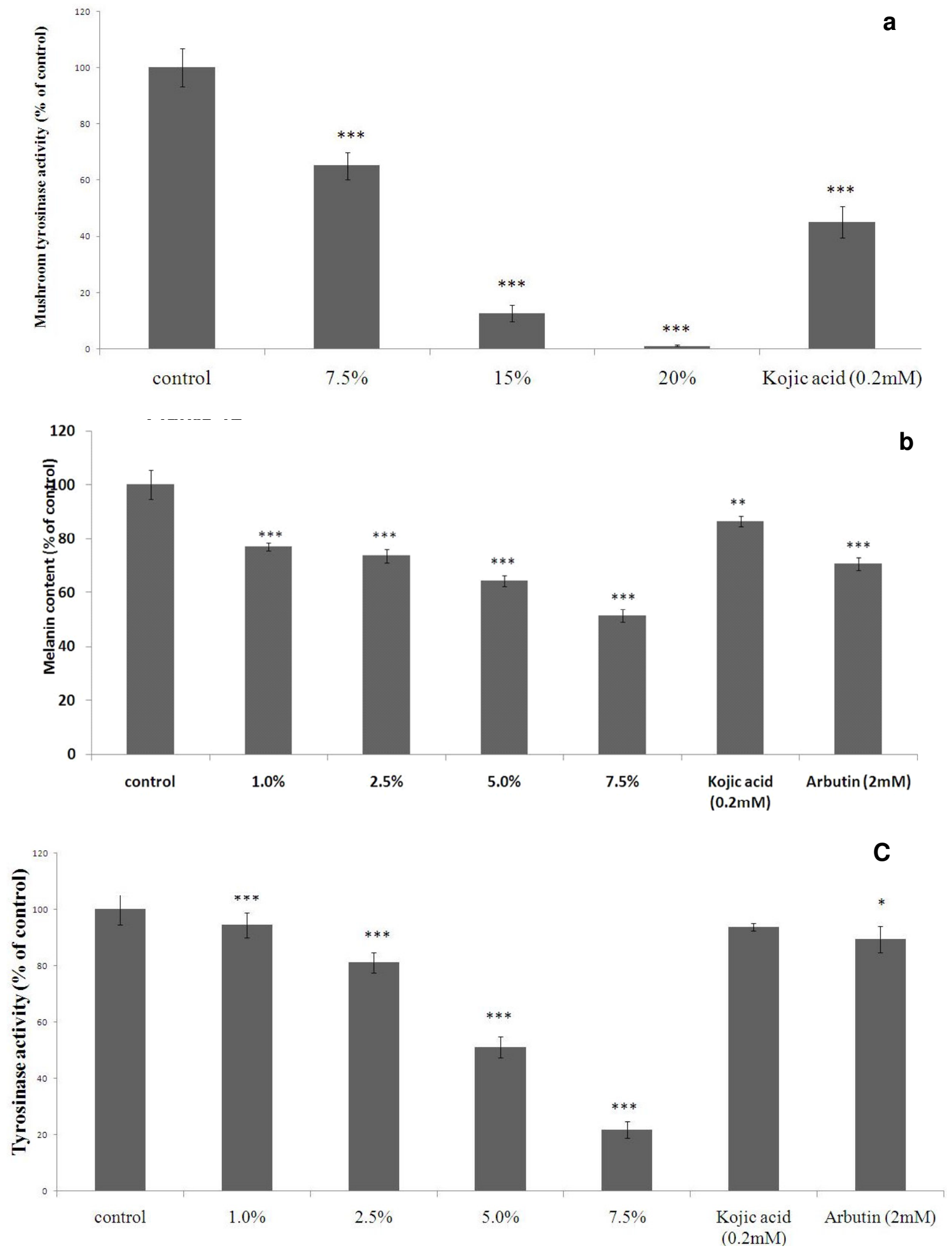

Figure 1. Whitening effect of $B$. infantis culture filtrate. A. Mushroom tyrosinase activity assay. B. B16F10 melanin content determination. C. B16F10 intracellular tyrosinase activity measurements. Results are represented as percentages of control, and the data are presented as mean \pm S.D. of three separate experiments. Values are significantly different by comparison with the control. ${ }^{*} p<0.05 ;{ }^{* *} p<0.01 ;{ }^{* *} p<0.001$. 

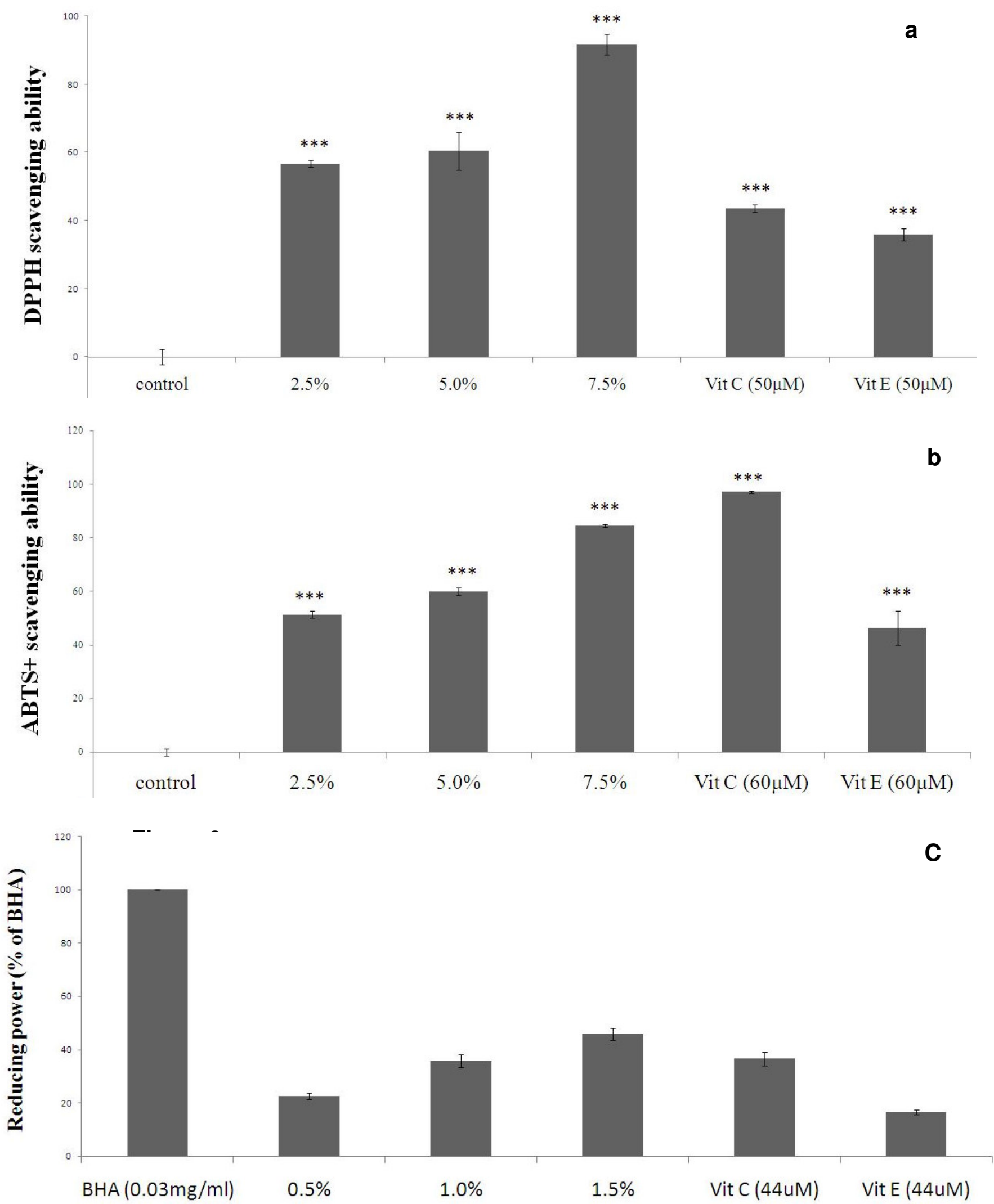

Figure 2. Antioxidant effects of $B$. infantis culture filtrate. A. Determination of DPPH scavenging capacity. B. ABTS ${ }^{+}$radical cation scavenging activity measurement. C. Reducing power assay. All assays were performed as described in Materials and methods. Values are represented as percentage of control. Data are means \pm S.D. of three separate experiments. ${ }^{*} p<0.05 ;{ }^{* *} p<0.01 ;{ }^{* * *} p<$ 0.001 . 
activity of vitamin $\mathrm{C}(60 \mu \mathrm{M})$ was $97.1 \pm 0.33 \%$ and that of $0.6 \%$, respectively. Meanwhile, the radical scavenging vitamin $\mathrm{E}(60 \mu \mathrm{M})$ was $46.4 \pm 6.3 \%$. The reducing power of $B$. infantis culture filtrate increased steadily with the increasing concentration (Figure $2 \mathrm{C}$ ). In this study, the reducing power of bacterial filtrate, vitamin $\mathrm{C}$ and vitamin $\mathrm{E}$ was compared with that of butylated hydroxyanisole (BHA) $(0.03 \mathrm{mg} / \mathrm{ml})$. The reducing power for $0.5,1.0$ and $1.5 \%$ of bacterial culture filtrate was $22.5 \pm 1.2,35.7 \pm$ $2.4,45.8 \pm 2.3 \%$, respectively. Meanwhile, the reducing power of vitamin $\mathrm{C}(44 \mu \mathrm{M})$ was $36.5 \pm 2.5 \%$ and that of vitamin $\mathrm{E}(44 \mu \mathrm{M})$ was $16.4 \pm 0.8 \%$. This is the first report about the effect of $B$. infantis culture filtrate on melanin production. In the present study, it is found that $B$. infantis culture filtrate inhibit melanin synthesis significantly in a dose-dependent pattern. Besides, $B$. infantis culture filtrate also expresses potent antioxidant activity. The results suggested that $B$. infantis culture filtrate decreased melanin production may be attributed to its inhibitory action upon the signaling pathway regulating tyrosinase activity or depletion of cellular ROS. We will study the effects of various protein kinase inhibitors on melanogenesis in $B$. infantis culture filtrate treated B16F10 melanoma cells in the near future. Certainly, we will also analyze the active components in the $B$. infantis culture filtrate and elucidate the antioxidant and whitening mechanisms.

\section{ACKNOWLEDGEMENTS}

The authors gratefully acknowledge financial support by grants from Ministry of Economic Affairs, Republic of China. (98-EC-17-A-17-S1-128 and S09900074-603).

\section{REFERENCES}

Bilodeau M, Greulich J, Hullinger R, Bertolotto C, Ballotti R, Andrisani O (2001). BMP-2 stimulates tyrosinase gene expression and melanogenesis in differentiated melanocytes. Pigment Cell Res., 14(5): 328-336.

Ballotti R (2000). Cyclic AMP a key messenger in the regulation of skin pigmentation. Pigment Cell Res., 13(2): 60-69.

Brand-Williams W, Cuvelier M, Berset C (1995). Use of a free radical method to evaluate antioxidant activity. LWT-Food Sci. Technol., 28(1): 25-30.

Briganti S, Camera E, Picardo M (2003). Chemical and instrumental approaches to treat hyperpigmentation. Pigment Cell Res., 16(2): 101-110.

Cinque B, Di Marzio L, Della Riccia D, Bizzini F, Giuliani M, Fanini D, De Simone C and Cifone M (2006). Effect of Bifidobacterium infantis on interferon-gamma-induced keratinocyte apoptosis: a potential therapeutic approach to skin immune abnormalities. Int. J. Immunopathol. Pharmacol., 19(4): 775-786.

Emerit I (1992). Free radicals and aging of the skin. EXS., 62: 328-341.

Femia A, Luceri C, Dolara P, Giannini A, Biggeri A, Salvadori M, Clune Y, Collins K, Paglierani M, Caderni G (2002). Antitumorigenic activity of the prebiotic inulin enriched with oligofructose in combination with the probiotics Lactobacillus rhamnosus and Bifidobacterium lactis on azoxymethane-induced colon carcinogenesis in rats. Carcinogenesis, 23(11): 1953-1960.

Funasaka Y, Komoto M, Ichihashi M (2000). Depigmenting effect of alpha- tocopheryl ferulate on normal human melanocytes. Pigment Cell Res., 13(Suppl 8): 170-174.

Gibson G, Wang X (1994). Regulatory effects of bifidobacteria on the growth of other colonic bacteria. J. Appl. Bacteriol., 77(4): 412-420.

Gilliland S (1990). Health and nutritional benefits from lactic acid bacteria. FEMS Microbiol. Rev., 7(1-2): 175-188.

Halliwell B, Gutteridge J and Cross C (1992). Free radicals, antioxidants, and human disease: where are we now? J. Lab. Clin. Med., 119(6): 598-620.

Hearing V, Jimenez M (1987). Mammalian tyrosinase--the critical regulatory control point in melanocyte pigmentation. Int. J. Biochem., 19(12): 1141-1147.

Hooper L, Gordon J (2001). Commensal host-bacterial relationships in the gut. Science., 292: 1115-1118.

Ichihashi M, Ueda M, Budiyanto A (2003). UV-induced skin damage. Toxicology, 189(1-2): 21-39.

Imokawa G (1989). Analysis of initial melanogenesis including tyrosinase transfer and melanosome differentiation though interrupted melanization by glutathione. J. Invest. Dermatol., 93(1): 100-107.

Jimenez-Cervantes C, Solano F, Kobayashi T, Urabe K, Hearing V, Lozano J, Garcia-Borron J (1994). A new enzymatic function in the melanogenic pathway. The 5, 6-dihydroxyindole-2-carboxylic acid oxidase activity of tyrosinase-related protein-1 (TRP1). J. Biol. Chem., 269(27): 17993-18000.

Kalliomaki M, Salminen S, Arvilommi H, Kero P, Koskinen P, Isolauri E (2001). Probiotics in primary prevention of atopic disease: a randomised placebo-controlled trial. Lancet., 357: 1076-1079.

Kalliomaki M, Salminen S, Poussa T, Arvilommi H, Isolauri E (2003). Probiotics and prevention of atopic disease: 4-year follow-up of a randomised placebo-controlled trial. Lancet., 361: 1869-1871.

Kalliomaki M, Salminen S, Poussa T, Isolauri E (2007). Probiotics during the first 7 years of life: a cumulative risk reduction of eczema in a randomized, placebo-controlled trial. J. Allergy Clin. Immunol., 119(4): 1019-1021.

Kumano Y, Sakamoto T, Egawa M, Iwai I, Tanaka M, Yamamoto I (1998). In vitro and in vivo prolonged biological activities of novel vitamin $C$ derivative, 2-O-alpha-D-glucopyranosyl-L-ascorbic acid (AA-2G), in cosmetic fields. J. Nutr. Sci. Vitaminol., 44(3): 345-359.

Mukhtar H, Elmets CA (1996). Photocarcinogenesis: mechanisms, models and human health implications. Photochem. Photobiol., 63(4): 356-357.

Ouwehand A, Batsman A, Salminen S (2003). Probiotics for the skin: a new area of potential application? Lett. Appl. Microbiol., 36(5): 327331

Ouwehand A, Isolauri E, Salminen S (2002). The role of the intestinal microflora for the development of the immune system in early childhood. Eur. J. Nutr., 41 (Suppl 1): 132-137.

Oyaizu M (1986). Studies on the products of browning reaction prepared from glucose amine. Jpn. J. Nutr., 44: 307-315.

Puch F, Samson-Villeger S, Guyonnet D, Blachon J, Rawlings A, Lassel $T$ (2008). Consumption of functional fermented milk containing borage oil, green tea and vitamin $E$ enhances skin barrier function. Exp. Dermatol., 17(8): 668-674.

Rautava S, Isolauri E (2002). The development of gut immune responses and gut microbiota: effects of probiotics in prevention and treatment of allergic disease. Curr. Issues Intest. Microbiol., 3(1): 1522.

Re R, Pellegrini N, Proteggente A, Pannala A, Yang M, Rice-Evans C (1999). Antioxidant activity applying an improved ABTS radical cation decolorization assay. Free Radic. Biol. Med., 26(9-10): 1231-1237.

Rodrigues K, Caputo L, Carvalho J, Evangelista J, Schneedorf J (2005). Antimicrobial and healing activity of kefir and kefiran extract. Int. J. Antimicrob. Agents., 25(5): 404-408.

Sanchez-Moreno C, Larrauri J and Saura-Calixto F (1998). A procedure to measure the antiradical efficiency of polyphenols. J. Sci. Food Agric., 76(2): 270-276.

Seo S, Sharma V, Sharma N (2003). Mushroom tyrosinase: recent prospects. J. Agric. Food Chem., 51(10): 2837-2853.

Tanabe S, Kinuta Y, Saito Y (2008). Bifidobacterium infantis suppresses proinflammatory interleukin-17 production in murine splenocytes and dextran sodium sulfate-induced intestinal inflammation. Int. J. Mol. 
Med., 22(2): 181-185.

Tsuboi T, Kondoh H, Hiratsuka J, Mishima Y (1998). Enhanced melanogenesis induced by tyrosinase gene-transfer increases boronuptake and killing effect of boron neutron capture therapy for amelanotic melanoma. Pigment Cell Res., 11(5): 275-282.

Tsukamoto K, Jackson I, Urabe K, Montague P, Hearing V (1992). A second tyrosinase-related protein, TRP-2, is a melanogenic enzyme termed DOPAchrome tautomerase. EMBO J., 11(2): 519-526.

Van der Kleij H, O'Mahony C, Shanahan F, O'Mahony L, Bienenstock J (2008). Protective effects of Lactobacillus reuteri and Bifidobacterium infantis in murine models for colitis do not involve the vagus nerve. Am. J. Physiol. Regul. Integr. Comp. Physiol., 295(4): R1131-R1137.
Yamakoshi J, Otsuka F, Sano A, Tokutake S, Saito M, Kikuchi M, Kubota $Y$ (2003). Lightening effect on ultraviolet-induced pigmentation of guinea pig skin by oral administration of a proanthocyanidin-rich extract from grape seeds. Pigment Cell Res., 16(6): 629-638.

Yasui H, Sakurai H (2003). Age-dependent generation of reactive oxygen species in the skin of live hairless rats exposed to UVA light. Exp. Dermatol., 12(5): 655-661.

Yeh Yang J, Hyun Koo J, Gil Song Y, Beom Kwon K, Hyung Lee J, Sook Sonh H, Hyun Park B, Chung Jhee E, Woo Park J (2006). Stimulation of melanogenesis by scoparone in B16 melanoma cells. Acta Pharmacol. Sin., 27(11): 1467-1473. 